\title{
Serum PSA and Percent Free PSA Value Changes after Antibiotic Treatment
}

\author{
A Diagnostic Method in Prostate Cancer Suspects with Asymptomatic Prostatitis
}

\author{
Minoru Kobayashi ${ }^{a}$ b Akinori Nukui $^{a}$ Tatsuo Morita ${ }^{a}$

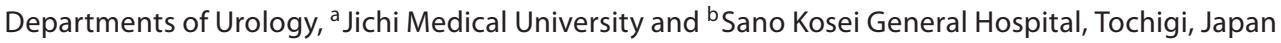

\section{Key Words}

Prostate-specific antigen - Percent free prostate-specific antigen - Prostate cancer · Subclinical prostatitis ·

Antibiotics, prostate-specific antigen

\begin{abstract}
Introduction: An association between inflammatory foci in prostatic tissues and elevated serum prostate-specific antigen (PSA) levels has been a controversial issue. We studied the effects of antibiotics on elevated PSA levels to improve the diagnostic value of prostate cancer findings. Patients and Methods: Of 65 asymptomatic men with inconstant PSA elevation, 51 with laboratory signs of prostatitis received antibiotics instead of undergoing a prompt prostate biopsy. Asymptomatic prostatic inflammation was defined as the presence of $>10$ white blood cells/high-power field in the post-prostate massage urine. Follow-up measurements of PSA and percent free PSA values were obtained. Results: Approximately $30 \%$ of the patients had a treatment response, defined as PSA decrease $>20 \%$ from baseline. The range of the variations of PSA and percent free PSA values, expressed as coefficient of variation, also decreased significantly. Moreover, antibiotic treatment lowered the extent of histological prostatic inflammation in some patients. Conclusions: Sub-
\end{abstract}

clinical prostatic inflammation potentially contributes to an elevated PSA level and its variation among prostate cancer suspects. Watchful observation may be an optional tool for patients showing a significant PSA decrease following antibiotic treatment.

Copyright $\odot 2008$ S. Karger AG, Basel

\section{Introduction}

Prostate-specific antigen (PSA) is the most powerful serum marker for detecting and monitoring prostate cancer. However, the specificity of PSA is not high, i.e., approximately $70 \%$ of the biopsy specimens fail to indicate cancer, when the criterion is a PSA level of between 4 and $10 \mathrm{ng} / \mathrm{ml}$ [1]. Benign prostatic hyperplasia (BPH) and prostatitis are the most frequent causes of intermediate PSA elevations which lead to unnecessary prostate biopsies [2-4]. Percent free PSA (\%f-PSA) has been used to increase the specificity of PSA screening and to avoid unnecessary biopsies [5-7]; however, \%f-PSA is unlikely to reliably discriminate between prostate cancer and prostatitis [8-11].

In addition, controversy remains regarding the effect of subclinical prostatic inflammation classified as $\mathrm{Na}$ -

\section{KARGER}

Fax +4161306 1234

E-Mail karger@karger.ch

www.karger.com
(C) 2008 S. Karger AG, Basel

0042-1138/08/0802-0186\$24.50/0

Accessible online at:

www.karger.com/uin
Minoru Kobayashi, MD

Department of Urology, Jichi Medical University

3311-1 Yakushiji, Shimotsuke-shi

Tochigi 329-0498 (Japan)

Tel. +81 28558 7379, Fax +81 28540 6595, E-Mail minoruk@jichi.ac.jp 
tional Institutes of Health category IV prostatitis on serum PSA levels [10-24]. Moreover, few data are available on changes in PSA values after antibiotic treatment of patients with asymptomatic prostatic inflammation and elevated PSA values as a diagnostic tool for prostate cancer screening [25-30].

Intraindividual physiological variations in PSA and \%f-PSA levels have been reported [31-35]. Therefore, PSA measurements must be repeated before performing prostate biopsies for elevated PSA values to avoid unnecessary biopsy procedures. However, many urologists hesitate to perform a prostate biopsy because of variations in these parameters between repeated measurements, especially in patients who have already undergone a first benign biopsy diagnosis. It is not fully understood what causes the physiological variation in serum PSA, and we speculate that subclinical prostatic inflammation may contribute to the variations.

Therefore, we investigated the effects of antibiotic treatment on serum PSA and \%f-PSA levels and their variations in individuals with asymptomatic prostatic inflammation to investigate its feasibility in improving screening accuracy of prostate cancer.

\section{Patients and Methods}

From September 2003 to June 2005, 178 men with PSA levels $>4 \mathrm{ng} / \mathrm{ml}$ were referred for urological evaluation. Those with acute urinary infection, acute urinary retention, suspicious results of digital rectal examination, and steady rises in repeated PSA measurements were excluded from the study, leaving 65 men (mean age 68.5 years) for whom we hesitated to perform prompt biopsy because their PSA values rose and fell inconstantly in repeated measurements. These men were assessed for a laboratory sign of prostatitis, although none of them had a clinical sign of prostatitis in subjective symptoms or objective findings on digital rectal examination. To identify asymptomatic inflammation in the prostatic tissue, we used the pre- and post-prostatemassage test introduced by Nickel [36]. Briefly, after first urination, the patients provided another urine specimen (substitution for voiding bottle 3; VB3) following vigorous prostate massage. The specimen was microscopically examined, and asymptomatic prostatic inflammation was defined as the presence of $>10$ white blood cells/high-power field in VB3. Consequently, 51 patients with positive VB3 results entered the study and received levofloxacin $300 \mathrm{mg} /$ day for 4 weeks. PSA and \%f-PSA were measured before and 4 weeks after completion of the treatment. PSA and \%f-PSA change rates after antibiotic treatment were calculated as follows: PSA change rate $(\%)=(\Delta \mathrm{PSA} /$ baseline PSA $) \times 100, \Delta \mathrm{PSA}=$ posttreatment PSA - baseline PSA; \%f-PSA change rate $(\%)=$ $(\Delta \% \mathrm{f}$-PSA/baseline $\% \mathrm{f}-\mathrm{PSA}) \times 100, \Delta \% \mathrm{f}-\mathrm{PSA}=$ posttreatment $\%$ fPSA - baseline \%f-PSA.

Considering the physiological variations in PSA and \%f-PSA $[29-35,37]$, changes $>20 \%$ were considered meaningful. When the posttreatment PSA value decreased $>20 \%$ from baseline, antibiotic treatment was considered effective, and the patient was defined as a responder. A prostate biopsy was recommended to patients who failed to obtain a PSA response, especially when they had not undergone biopsies within 1 year before study entry. In addition, even responders were encouraged to undergo a prostate biopsy, when the PSA level stayed at $10 \mathrm{ng} / \mathrm{ml}$ or higher which is considered a range of a high incidence of having cancer. In ultrasound-guided transperineal systematic biopsies, the prostate volume was measured, and samples from 10 to 18 cores were obtained.

Physiological variation was defined as the mean coefficient of variation (CV) of PSA and \%f-PSA. The CV was calculated by dividing the standard deviation of the repeated values by the mean values. Total PSA and \%f-PSA were monitored every 3 months before and after the posttreatment measurement over 1 year. If biopsies were performed during this period, measurements were done no less than 90 days after the biopsies. All patients were provided with a detailed explanation of the study, and written informed consent was obtained.

One pathologist made all pathological diagnoses. The degree of prostatic inflammation was evaluated on the basis of intensity and extent. The intensity of the inflammation in each specific location was categorized into three grades: $1=$ mild; $2=$ moderate, and $3=$ severe, according to the classification system of prostatic inflammatory changes [38]. The most severe grade throughout the specimens was recorded as the inflammation intensity in each case. The extent of inflammation was expressed as percentage of positive cores which was calculated as the ratio of positive cores to the total obtained cores multiplied by 100 .

\section{PSA and \%f-PSA Determinations}

We measured total and free PSA using Tandem- $\mathrm{R}^{\mathrm{TM}}$, a monoclonal assay with a lower limit of detection of $0.1 \mathrm{ng} / \mathrm{ml}$. The \%fPSA was calculated as the ratio of free to total PSA multiplied by 100. The intra-assay CV fluctuated between 1.55 and $8.47 \%$ (obtained by 40 measurements of PSA levels ranging from 0.55 to $211.16 \mathrm{ng} / \mathrm{ml}$ ), and the interassay CV fluctuated between 1.69 and $5.04 \%$ for total PSA (obtained by 20 measurements of PSA levels ranging from 0.57 to $41.59 \mathrm{ng} / \mathrm{ml}$ ). Regarding free PSA, the intraassay CV fluctuated between 1.75 and 3.70\% (obtained by 15 measurements of PSA levels ranging from 1.31 to $11.60 \mathrm{ng} / \mathrm{ml}$ ), and the interassay CV fluctuated between 1.69 and 5.04\% (obtained by 16 measurements of PSA levels ranging from 1.31 to $11.76 \mathrm{ng} /$ $\mathrm{ml}$ ). Serum provided by the manufacturer (PSA diluted by fetal bovine serum with phosphate buffer to concentrations of $0.3,3$, and $40 \mathrm{ng} / \mathrm{ml}$ ) served as the quality control material and was monitored on a daily basis to confirm assay stability. Sera were collected and assayed on the same day using the same lot of reagents which were changed every 2 weeks. The cutoff values were $4.0 \mathrm{ng} / \mathrm{ml}$ for total PSA and $25 \%$ for $\%$ f-PSA.

\section{Statistics}

The results are expressed as mean $\pm \mathrm{SD}$. The data were analyzed by Wilcoxon test for related data, Mann-Whitney U test for independent data, and chi-square analysis. These analyses were performed using StatView 5.5 software. Results were considered statistically significant when $\mathrm{p}<0.05$. 
Table 1. PSA and \%f-PSA levels and $\mathrm{CV}$ values before and after antibiotic treatment

\begin{tabular}{llll}
\hline & $\begin{array}{l}\text { Before } \\
\text { treatment }\end{array}$ & $\begin{array}{l}\text { After } \\
\text { treatment }\end{array}$ & $\begin{array}{l}\mathrm{p} \\
\text { (Wilcoxon) }\end{array}$ \\
\hline PSA, ng/ml & $\begin{array}{l}11.49 \pm 8.75 \\
\text { (range 4.6-44) }\end{array}$ & $\begin{array}{l}10.24 \pm 7.96 \\
\text { (range 1.2-41) }\end{array}$ & 0.0088 \\
\%f-PSA & $\begin{array}{l}16.88 \pm 8.27 \\
\text { (range 6-39) }\end{array}$ & $\begin{array}{l}16.97 \pm 8.12 \\
\text { (range 5-43) }\end{array}$ & 0.9713 \\
CV of PSA, \% & $19.35 \pm 17.89$ & $14.38 \pm 13.67$ & 0.0277 \\
CV of \%f-PSA & $13.43 \pm 13.64$ & $13.70 \pm 8.85$ & 0.9721 \\
\hline
\end{tabular}

Table 2. Clinical characteristics according to PSA response to antibiotic treatment

\begin{tabular}{lccc}
\hline & $\begin{array}{l}\text { Responders } \\
(\mathrm{n}=15)\end{array}$ & $\begin{array}{l}\text { Nonresponders } \\
(\mathrm{n}=36)\end{array}$ & $\begin{array}{l}\mathrm{p} \text { (Mann- } \\
\text { Whitney) }\end{array}$ \\
\hline Age, years & $65.2 \pm 12.8$ & $69.3 \pm 7.6$ & 0.6791 \\
Prostate volume, ml & $32.0 \pm 9.6$ & $36.8 \pm 16.8$ & 0.7571 \\
Baseline PSA, ng/ml & $12.92 \pm 10.71$ & $10.89 \pm 7.89$ & 0.8442 \\
Baseline \%f-PSA & $21.09 \pm 10.69$ & $15.38 \pm 6.83$ & 0.1362 \\
Pretreatment CV of PSA, \% & $32.65 \pm 23.11$ & $14.77 \pm 13.30$ & 0.0279 \\
Pretreatment CV of \%f-PSA & $20.06 \pm 21.25$ & $10.71 \pm 8.43$ & 0.4455 \\
\hline
\end{tabular}

\section{Results}

All VB3-positive patients were treated with levofloxacin. A PSA level decrease was observed in 33 of the 51 patients (65.1\%), while 14 of the 51 patients (27.4\%) showed a rise in PSA levels after antibiotic treatment. The PSA levels did not change in 4 patients. A treatment PSA response defined as a $>20 \%$ decrease from baseline was achieved in 15 cases (29.4\%), in whom the PSA values markedly decreased $(\mathrm{p}=0.0007)$ from $12.92 \pm 10.71$ to $7.00 \pm 5.87 \mathrm{ng} / \mathrm{ml}$ after treatment. Of 15 responders, a PSA decrease below the cutoff value of $4 \mathrm{ng} / \mathrm{ml}$ occurred in 5 patients, while PSA value did not fall to $<10 \mathrm{ng} / \mathrm{ml}$ in 1 patient. As shown in table 1, the overall PSA values decreased significantly after antibiotic treatment $(\mathrm{p}=$ 0.0088 ), while the $\% f-P S A$ values did not change. A similar trend was observed in the CV of PSA and in the CV of \%f-PSA changes, i.e., a significant decrease was observed in the CV of PSA, but not in the CV of \%f-PSA after antibiotic treatment.

The clinical characteristics of the groups according to treatment PSA response were comparable, except for the pretreatment CV of PSA. The pretreatment CV of PSA was significantly higher in responders than that in nonresponders $(\mathrm{p}=0.0279$; table 2$)$.
Table 3. Case distribution stratified by histology and PSA response to antibiotic treatment

\begin{tabular}{|c|c|c|c|}
\hline & \multicolumn{3}{|c|}{ Treatment PSA response } \\
\hline & $\begin{array}{l}\text { responders } \\
(\mathrm{n}=9)\end{array}$ & $\begin{array}{l}\text { nonresponders } \\
(\mathrm{n}=31)\end{array}$ & $\begin{array}{l}\mathrm{p} \\
\left(\chi^{2}\right)\end{array}$ \\
\hline No cancer $(\mathrm{n}=23)$ & 9 & 22 & \\
\hline Cancer $(\mathrm{n}=7)$ & 0 & 19 & 0.0897 \\
\hline
\end{tabular}

Consequently, prostate biopsies were performed in 40 (78.4\%) of the 51 VB3-positive patients. Eleven patients (6 responders and 5 nonresponders) did not undergo prostate biopsy. Thus, 5 patients $(9.8 \%)$ did not follow the aforementioned biopsy criteria, and in whom extended PSA follow-up is preferred.

Of the 40 biopsied patients, cancer was diagnosed in 9 (22.5\%) and noncancer in 31 (normal prostatic tissue in 14 , BPH in 9, atypical adenomatous hyperplasia in 5, or prostatic intraepithelial hyperplasia in 3 cases, none of them was high grade). An association between histological profile and treatment outcome was examined (table 3). Although all responders who underwent prostate biopsies turned out to have no cancer, the case distribu- 
Table 4. Degree of prostatic inflammation according to treatment response, VB3 result, or histology

\begin{tabular}{|c|c|c|}
\hline & $\begin{array}{l}\text { Cores positive } \\
\text { for inflammation, } \%\end{array}$ & $\begin{array}{l}\text { Inflammatory } \\
\text { grade }\end{array}$ \\
\hline \multicolumn{3}{|l|}{ Treatment PSA response } \\
\hline Responders $(n=6)$ & $79.9 \pm 18.3$ & $1.83 \pm 0.40$ \\
\hline Nonresponders $(\mathrm{n}=21)$ & $54.4 \pm 19.1$ & $1.61 \pm 0.59$ \\
\hline $\mathrm{p}$ (Mann-Whitney) & 0.0194 & 0.3432 \\
\hline \multicolumn{3}{|l|}{ Histology } \\
\hline Cancer $(\mathrm{n}=4)$ & $57.7 \pm 2.2$ & $1.50 \pm 0.50$ \\
\hline No cancer $(\mathrm{n}=23)$ & $59.2 \pm 24.4$ & $1.67 \pm 0.56$ \\
\hline p (Mann-Whitney) & 0.7582 & 0.5262 \\
\hline
\end{tabular}

Inflammation was categorized into three grades: $1=$ mild, $2=$ moderate, and 3 = severe, according to the classification system of prostatic inflammatory changes [38]. Percent positive cores were calculated as the ratio of positive cores to the total obtained cores multiplied by 100 . No cancer includes normal prostatic tissue, $\mathrm{BPH}$, prostatic intraepitherial hyperplasia, and atypical adenomatous hyperplasia.

Table 5. Changes in the degree of prostatic inflammation in biopsied samples following antibiotic treatment

\begin{tabular}{llll}
\hline & $\begin{array}{l}\text { Before } \\
\text { treatment }\end{array}$ & $\begin{array}{l}\text { After } \\
\text { treatment }\end{array}$ & $\begin{array}{l}\mathrm{p} \\
\text { (Wilcoxon) }\end{array}$ \\
\hline $\begin{array}{c}\text { Cores positive for } \\
\text { inflammation }\end{array}$ & $65.7 \pm 14.4$ & $31.6 \pm 23.2$ & 0.0125 \\
Inflammation grade & $1.60 \pm 0.51$ & $1.70 \pm 0.67$ & 0.5637 \\
\hline
\end{tabular}

tion as a function of treatment response and histological outcome did not reach statistical significance $(\mathrm{p}=$ 0.0897).

Prostatic inflammatory foci were detected in all patients examined. Most of the inflammatory foci in the prostatic tissues were graded as mild to moderate. The relations between degree of inflammation and treatment response or histological characteristics were examined (table 4). Only samples from 27 patients obtained before antibiotic treatment were used in this analysis to avoid a possible effect on inflammatory findings by the treatment. Percent positive cores with inflammation were significantly more often present in responders as compared with nonresponders $(\mathrm{p}=0.0194)$, whereas the grade of inflammation did not differ, regardless of the treatment response. There was no differ- ence in the inflammatory extent between cancerous and noncancerous tissues. Finally, the effect of antibiotic treatment on inflammatory findings in the prostatic tissue was examined (table 5). Among the treated cases, samples obtained both before and after treatment were available from 10 patients. The percent positive cores of inflammation decreased markedly following treatment $(\mathrm{p}=0.025)$, while the inflammatory grade did not change.

\section{Discussion}

When a patient has biochemical criteria arguing for prostate biopsy, many urologists prefer to repeat PSA measurements to confirm an increase in the value before performing a biopsy. Nevertheless, we often encounter difficulties in interpreting the measurements when the values fluctuate. This variation is thought to be partly the result of intraindividual physiological variation, ranging from 6.2 to $58 \%$, depending on sampling interval and subjects [37].

Although controversy remains, some investigators reported that subclinical prostatic inflammation could cause an increase in PSA values [9-13, 15, 16, 20, 21, 24]. However, less attention has been paid to this nonacute type of inflammation which could be a more common phenomenon among the screened population as compared with acute prostatitis. Therefore, the effect of subclinical inflammation on the PSA value is of great interest with respect to improving screening accuracy.

Thus far, little is known about the effect of antibiotic treatment on PSA levels for prostate cancer screening. Potts [25] reported that the PSA value returns to the normal range in $43 \%(22 / 51)$ of the patients with laboratory signs of prostatitis (positive VB3 result) after antibiotic treatment and recommended that screening for National Institutes of Health category IV prostatitis should be considered in men with an elevated PSA value. Karazanashvili and Managadze [26] reported that antibiotic treatment led to a decrease of over $6 \%$ from the baseline PSA value in $80 \%(49 / 61)$ of the patients with prostatic inflammation and a PSA value of between 4 and $10 \mathrm{ng} / \mathrm{ml}$, indicating that it is a reproducible method for reducing the number of unnecessary biopsies. Lorente et al. [27] treated 45 patients with a history of lower urinary tract infection with antibiotics, resulting in a significant decrease in the PSA value and in an increase in the \%f-PSA value in those with prostatitic foci associated with BPH but not in those with $\mathrm{BPH}$ without prostatitis or cancer in the sub- 
sequent biopsy specimen. Bozeman et al. [28] reported that the PSA level decreased by $36 \%$ from the baseline value after treatment with antibiotics and nonsteroidal anti-inflammatory agents in 95 men with chronic prostatitis and that almost half achieved a normal PSA value and no longer required prostate biopsy. Erol et al [30] suggested antibiotic treatment in patients with elevated PSA levels to discriminate between benign and malignant prostate pathologies, reporting that treatment for a subclinical prostatitis likely resulted in a PSA level decrease which was significant only in benign conditions. According to these limited reports, antibiotic treatment may cause a decrease in the PSA value in patients with subclinical prostatic inflammation and seems to favor screening efficiency.

Thus, we investigated whether not only the effect of antibiotic treatment on serum PSA and \%f-PSA levels but also possible variations in these parameters resulting from antibiotic treatment contribute to correct interpretation in enhancing the efficiency of prostate biopsies. Similar to previous reports, the overall PSA level decreased significantly after antibiotic treatment in patients with subclinical prostatic inflammation. Pretreatment CVs of PSA and \%f-PSA were equal to those reported previously $[31-35,37]$. However, it is of note that the variation in PSA levels significantly decreased after antibiotic treatment. Moreover, the variation in pretreatment PSA levels was higher in responders who had a marked PSA decrease after antibiotic treatment (table 1). These findings suggest that subclinical prostatic inflammation would be one of the contributors to the physiological variations in PSA values. Thus, repeated PSA measurements would be more accurate when the PSA variation is diminished following antibiotic treatment. By contrast, antibiotic treatment did not affect either the \%f-PSA or its variation. Therefore, repeated \%f-PSA measurements seem irrelevant as a diagnostic tool under antibiotic treatment.

Approximately $30 \%$ of our treated patients achieved a significant decrease in the PSA values, i.e., more than a $20 \%$ decrease from the baseline level which is beyond the range of the mean physiological variation [37]. One might suggest that such a definition of the PSA response on the basis of one measurement after antibiotic treatment would be a problem in patients with fluctuating PSA values. However, the majority of the patients did not show a PSA increase but a decrease after antibiotic treatment, and the variation in PSA levels was significantly lowered after treatment. Therefore, we considered that more than a 20\% decrease in PSA levels from baseline was not a sign of physiological variation, but caused by the treatment itself.

To the best of our knowledge, no study has ever analyzed the association between treatment response in PSA levels and inflammatory degree in the prostatic tissue. The inflammatory intensity was generally mild in subclinical prostatitis. The treatment response was associated with the inflammatory extent but not with the intensity. Moreover, the inflammatory extent was significantly lower in the prostatic tissues obtained following antibiotic treatment than in tissues obtained prior to the treatment in the same individual. Taken together, we can speculate that antibiotic treatment results in a decrease in PSA levels, when mild inflammation is present extensively in the prostatic tissue. On the other hand, the PSA response after antibiotic treatment was not a definitive predictor of histological characteristics (table 3). This is probably because subclinical prostatic inflammation has less impact on the PSA values as compared with a malignant condition, even though there was no difference in the inflammatory extent between cancerous and noncancerous tissues. However, it should be noted that all cases showing a PSA treatment response turned out to be noncancerous which may suggest that prostate biopsies could be postponed in such cases. This finding concurs with the recent findings of Erol et al. [30], reporting that a significant decrease was seen in PSA levels in patients of the antibiotic treatment group with a histological diagnosis of inflammation and $\mathrm{BPH}$ instead of cancer. Since this was not the case among parallel subgroups in the nontreatment group, the authors concluded that the PSA response to antibiotic treatment was discriminating between benign and malignant conditions of the prostate.

The main limitation of the present study was that prostate biopsies were not performed in all cases, especially in those in whom the PSA values decreased after antibiotic treatment. Therefore, lowering the PSA values may not completely preclude performing a prostate biopsy to rule out the presence of cancer.

\section{Conclusions}

Subclinical prostatitis is a significant factor contributing to an increase in PSA values among patients screened for prostate cancer and may also contribute to a physiological variation in the PSA levels. It appears that antibiotic treatment may provide more acceptable initial treatment rather than proceeding directly to prostate biopsy 
in patients with a laboratory sign of prostatitis who show a fluctuating PSA elevation in repeated measurements. Prostate biopsies could be postponed and the patients managed with watchful observation, if antibiotic treat- ment leads to a significant decrease in PSA values and their variations. Further long-term follow-up studies are necessary in a large cohort of patients to define whether prostate biopsy can be excluded in such cases.

\section{References}

$>1$ Remzi M, Djavan B, Wammack R, Momeni M, Seitz C, Erne B, Dobrovits M, Alavi S, Marberger M: Can total and transition zone volume of the prostate determine whether to perform a repeat biopsy? Urology 2003;61: 161-166.

-2 Armitage TG, Cooper EH, Newling DW, Robinson MR, Appleyard I: The value of the measurement of serum prostate specific antigen in patients with benign prostatic hyperplasia and untreated prostate cancer. Br J Urol 1988;62:584-589.

$\checkmark 3$ Benson MC, Whang IS, Pantuck A, Ring K, Kaplan SA, Olsson CA, Cooner WH: Prostate specific antigen density: a means of distinguishing benign prostatic hypertrophy and prostate cancer. J Urol 1992;147(3 Pt 2):815-816.

$\checkmark 4$ Neal DE Jr, Clejan S, Sarma D, Moon TD: Prostate specific antigen and prostatitis. I. Effect of prostatitis on serum PSA in the human and nonhuman primate. Prostate 1992; 20:105-111.

$>5$ Reissigl A, Klocker H, Pointner J, Fink K, Horninger W, Ennemoser O, Strasser H, Colleselli K, Höltl L, Bartsch G: Usefulness of the ratio free/total prostate-specific antigen in addition to total PSA levels in prostate cancer screening. Urology 1996;48(6A suppl):62-66.

$\checkmark 6$ Recker F, Kwiatkowski MK, Piironen T, Petterson K, Goepel M, Scholl R: Free-to-total prostate-specific antigen (PSA) ratio improves the specificity for detecting prostate cancer in patients with prostatism and intermediate PSA levels. Br J Urol 1998;81:532538.

7 Woodrum DL, Brawer MK, Partin AW, Catalona WJ, Southwick PC: Interpretation of free prostate specific antigen clinical research studies for the detection of prostate cancer. J Urol 1998;159:5-12.

$>8$ Scattoni V, Raber M, Montorsi F, Da Pozzo L, Brausi M, Calori G, Freschi M, Rigatti P: Percent of free serum prostate-specific antigen and histological findings in patients undergoing open prostatectomy for benign prostatic hyperplasia. Eur Urol 1999;36:621630.

$>9$ Minardi D, Galosi AB, Recchioni A, Giammarco L, Polito M, Muzzonigro G: Diagnostic accuracy of percent free prostate-specific antigen in prostatic pathology and its usefulness in monitoring prostatic cancer patients. Urol Int 2001;67:272-282.
10 Stancik I, Lüftenegger W, Klimpfinger M, Müller MM, Hoeltl W: Effect of NIH-IV prostatitis on free and free-to-total PSA. Eur Urol 2004;46:760-764.

11 Rowe EW, Laniado ME, Walker MM, Anup $\mathrm{P}$ : Incidental acute prostatic inflammation is associated with a lower percentage of free prostate-specific antigen than other benign conditions of the prostate: a prospective screening study. BJU Int 2006;97:10391042.

12 Hasui Y, Marutsuka K, Asada Y, Ide H, Nishi S, Osada Y: Relationship between serum prostate specific antigen and histological prostatitis in patients with benign prostatic hyperplasia. Prostate 1994;25:91-96.

13 Nadler RB, Humphrey PA, Smith DS, Catalona WJ, Ratliff TL: Effect of inflammation and benign prostatic hyperplasia on elevated serum prostate specific antigen levels. J Urol 1995; 154(2 Pt 1):407-413.

14 Tchetgen MB, Oesterling JE: The effect of prostatitis, urinary retention, ejaculation, and ambulation on the serum prostate-specific antigen concentration. Urol Clin North Am 1997;24:283-291.

15 Irani J, Levillain P, Goujon JM, Bon D, Doré $\mathrm{B}$, Aubert J: Inflammation in benign prostatic hyperplasia: correlation with prostate specific antigen value. J Urol 1997;157:13011303.

16 Schatteman PH, Hoekx L, Wyndaele JJ, Jeuris W, Van Marck E: Inflammation in prostate biopsies of men without prostatic malignancy or clinical prostatitis: correlation with total serum PSA and PSA density. Eur Urol 2000;37:404-412.

17 Nickel JC, Downey J, Young I, Boag S: Asymptomatic inflammation and/or infection in benign prostatic hyperplasia. BJU Int 1999;84:976-981.

18 Morote J, Lopez M, Encabo G, de Torres IM: Effect of inflammation and benign prostatic enlargement on total and percent free serum prostatic specific antigen. Eur Urol 2000;37: 537-540.

19 Okada K, Kojima M, Naya Y, Kamoi K, Yokoyama K, Takamatsu T, Miki T: Correlation of histological inflammation in needle biopsy specimens with serum prostate-specific antigen levels in men with negative biopsy for prostate cancer. Urology 2000;55:892898
20 Yaman O, Göğüs C, Tulunay O, Tokatli Z, Ozden E: Increased prostate-specific antigen in subclinical prostatitis: the role of aggressiveness and extension of inflammation. Urol Int 2003;71:160-164.

21 Kwak C, Ku JH, Kim T, Park DW, Choi KY, Lee E, Lee SE, Lee C: Effect of subclinical prostatic inflammation on serum PSA levels in men with clinically undetectable prostate cancer. Urology 2003;62:854-859.

-22 Carver BS, Bozeman CB, Williams BJ, Venable DD: The prevalence of men with $\mathrm{Na}$ tional Institutes of Health category IV prostatitis and association with serum prostate specific antigen. J Urol 2003;169:589-591.

$\checkmark 23$ Simardi LH, Tobias-Machado M, Kappaz GT, Taschner Goldenstein P, Potts JM, Wroclawski ER: Influence of asymptomatic histologic prostatitis on serum prostate-specific antigen: a prospective study. Urology 2004; 64:1098-1101.

24 Gümüs BH, Nese N, Gündüz MI, Kandiloglu AR, Ceylan Y, Büyüksu C: Does asymptomatic inflammation increase PSA? A histopathological study comparing benign and malignant tissue biopsy specimens. Int Urol Nephrol 2004;36:549-553.

25 Potts JM: Prospective identification of $\mathrm{Na}$ tional Institutes of Health category IV prostatitis in men with elevated prostate specific antigen. J Urol 2000;164:1550-1553.

26 Karazanashvili G, Managadze L: Prostatespecific antigen (PSA) value change after antibacterial therapy of prostate inflammation, as a diagnostic method for prostate cancer screening in cases of PSA value within $4-10 \mathrm{ng} / \mathrm{ml}$ and nonsuspicious results of digital rectal examination. Eur Urol 2001;39: 538-543.

27 Lorente JA, Arango O, Bielsa O, Cortadellas R, Gelabert-Mas A: Effect of antibiotic treatment on serum PSA and percent free PSA levels in patients with biochemical criteria for prostate biopsy and previous lower urinary tract infections. Int J Biol Markers 2002; 17:84-89.

28 Bozeman CB, Carver BS, Eastham JA, Venable DD: Treatment of chronic prostatitis lowers serum prostate specific antigen. J Urol 2002;167:1723-1726.

29 Guercio S, Terrone C, Tarabuzzi R, Poggio M, Cracco C, Bollito E, Scarpa RM: PSA decrease after levofloxacin therapy in patients with histological prostatitis. Arch Ital Urol Androl 2004;76:154-158. 
30 Erol H, Beder N, Caliskan T, Dündar M, Unsal A, Culhaci N: Can the effect of antibiotherapy and anti-inflammatory therapy on serum PSA levels discriminate between benign and malign prostatic pathologies? Urol Int 2006;76:20-26.

31 Ornstein DK, Smith DS, Rao GS, Basler JW, Ratliff TL, Catalona WJ: Biological variation of total, free and percent free serum prostate specific antigen levels in screening volunteers. J Urol 1997;157:2179-2182.

32 Morote J, Raventós CX, Lorente JA, Enbabo G, López M, de Torres I: Intraindividual variations of total and percent free serum prostatic-specific antigen levels in patients with normal digital rectal examination. Eur Urol 1999;36:111-115.
33 Bunting PS, DeBoer G, Choo R, Danjoux C, Klotz L, Fleshner N: Intraindividual variation of PSA, free PSA and complexed PSA in a cohort of patients with prostate cancer managed with watchful observation. Clin Biochem 2002;35:471-475.

34 Kobayashi M, Kurokawa S, Tokue A: Intraindividual variation in total and percent free prostate-specific antigen levels in prostate cancer suspects. Urol Int 2005;74:198-202.

35 Bruun L, Becker C, Hugosson J, Lilja H, Christensson A: Assessment of intra-individual variation in prostate-specific antigen levels in a biennial randomized prostate cancer screening program in Sweden. Prostate 2005;65:216-221.
36 Nickel JC: The pre and post massage test (PPMT): a simple screen for prostatitis. Tech Urol 1997;3:38-43.

37 Söletormos G, Semjonow A, Sibley PE, Lamerz R, Petersen PH, Albrecht W, Bialk P, Gion M, Junker F, Schmid HP, Van Poppel H: Biological variation of total prostate-specific antigen: a survey of published estimates and consequences for clinical practice. Clin Chem 2005;51:1342-1351.

38 Nickel JC, True LD, Krieger JN, Berger RE, Boag AH, Young ID: Consensus development of a histopathological classification system for chronic prostatic inflammation. BJU Int 2001;87:797-805. 